\title{
Penggunaan Analgesia Nonfarmakologis Saat Tindakan Invasif Minor pada Neonatus
}

\author{
Effa Triani, Munar Lubis
}

Pada perawatan rutin neonatus sering dilakukan tindakan invasif minor yang menimbulkan rasa nyeri. Nyeri yang tidak ditanggulangi dapat menimbulkan efek jangka panjang yaitu mempengaruhi respon afektif dan tingkah laku saat tindakan yang menimbulkan nyeri berikutnya. Glukosa, sukrosa, pacifier, menyusui, skin to skin contact dan stimulasi multisensori merupakan analgesia nonfarmakologis yang dapat mengurangi rasa nyeri saat tindakan invasif minor pada neonatus, sehingga dapat dihindarkan pemakaian analgesia farmakologis yang sering menimbulkan efek samping.

Kata kunci: Analgesia nonfarmakologis, nyeri, neonatus

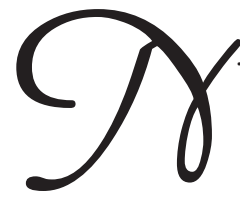
yeri merupakan suatu pengalaman sensorik dan emosional yang tidak menyenangkan dan merupakan tanda akan adanya kerusakan jaringan. ${ }^{1,2}$ Nyeri pada neonatus menjadi masalah oleh karena neonatus tidak dapat memberitahu rasa nyeri, kesulitan mengenali tangisan dan mimik wajah neonatus sebagai tanda rasa nyeri dan sulit menentukan kapan sebaiknya memberi analgesia pada neonatus. ${ }^{3}$

Sebelum tahun 1970 nyeri dan penanggulangan nyeri terfokus pada orang dewasa, sedangkan pada neonatus tidak adekuat. Analgesia atau anestesi tidak digunakan dengan berbagai alasan yaitu dapat menimbulkan komplikasi pada pembedahan serta nyeri tidak dapat diukur dan bayi tidak dapat mengingat nyeri.

\footnotetext{
Alamat korespondensi:

Prof. Dr. H. Munar Lubis, Sp A(K) Bagian Ilmu Kesehatan Anak Fakultas Kedokteran Universitas Sumatera Utara/ RSUP H.Adam Malik Jl. Bunga Lau no.17 Medan. Tel (061) 8361721 - 8365663 Fax. (061) 8361721 E-mail : bikafkusu@telkom.net; kotak Pos 697 Medan - 20136
}

Dr. Effa Triani Peserta program Dokter Spesialis Ilmu Kesehatan Anak FK-USU / RSHAM
Efek farmakologis analgesis dapat timbul adiksi dan diperkirakan tidak ada gejala sisa jangka panjang akibat nyeri pada neonatus. ${ }^{4}$ Beberapa dekade terakhir, berbagai mitos di atas sudah ditinggalkan. Sekarang telah diketahui bahwa struktur otak untuk ingatan jangka panjang telah berkembang secara adekuat pada neonatus dan karena itu ada efek jangka panjang akibat nyeri pada neonatus. Nyeri yang tidak ditanggulangi dapat mempengaruhi respon afektif dan tingkah laku saat tindakan nyeri selanjutnya. ${ }^{4}$

Neonatus hanya dapat mengkomunikasikan nyeri melalui perubahan tingkah laku dan perubahan fisiologis, misalnya ekspresi wajah, menggerakkan ekstremitas secara reflek, perubahan posisi tubuh dan menangis dengan nada yang tinggi dan keras. Ekspresi wajah dianggap merupakan indikator yang paling sensitif mengutarakan rasa nyeri pada neonatus. Aktifitas wajah dan gambaran wajah yang spesifik berhubungan dengan nyeri akut dalam waktu yang singkat. ${ }^{5}$ Perubahan fisiologis yang menunjukkan rasa nyeri pada neonatus misalnya perubahan warna kulit, telapak tangan berkeringat, penurunan saturasi oksigen, produksi hormon stres dan peningkatan frekuensi jantung, tekanan darah, respirasi, dan tekanan intra kranial. ${ }^{4,6}$ 
Penatalaksanaan nyeri dapat dilakukan dengan obatobatan (analgesia farmakologis) maupun dengan analgesia nonfarmakologis. Para klinisi meyakini bahwa analgesia farmakologis diberikan untuk tindakan yang sangat sakit (tindakan invasif mayor), sedangkan analgesia nonfarmakologis (glukosa, sukrosa, pacifier) kempeng, menyusui, skin to skin contact dan stimulasi multisensori) dipakai untuk prosedur yang lebih ringan rasa nyerinya (tindakan invasif minor). ${ }^{7}$ Selain itu pada tindakan invasif minor, penggunaan analgesia farmakologis diupayakan seminimal mungkin untuk menghindari efek samping. ${ }^{8-10}$

Tulisan ini bertujuan menjelaskan pemakaian glukosa, sukrosa, pacifier, menyusui, skin to skin contact dan stimulasi multisensori sebagai analgesia nonfarmakologis saat melakukan tindakan invasif minor pada neonatus

\section{Jaras Nyeri dan Inhibisi Nyeri}

Persepsi rasa nyeri pada neonatus memiliki jaras yang sama dengan dewasa. Stimulus mekanis, kimia atau termal akan merangsang nosiseptor dan aliran listrik berjalan ke kornu dorsalis medula spinalis melalui dua set serabut syaraf yaitu serabut A-delta (berdiameter kecil, bermyelin dan membawa sinyal nyeri secara cepat) dan serabut $\mathrm{C}$ (berdiameter kecil, tidak bermyelin, membawa sinyal nyeri secara lambat). ${ }^{2,11}$ Serabut syaraf yang mengandung stimulus nyeri berasal dari neuron pada substansia gelatinosa. Kemudian serabut syaraf berjalan kontralateral membentuk jaras spinotalamikus. Pada batang otak, informasi dari jaras spinotalamikus melewati formasio retikularis mengirim sinyal ke talamus dan terjadi persepsi nyeri. ${ }^{2}$ Neuron ini berakhir pada korteks sensori dan area basal otak yang mempengaruhi apresiasi terhadap kualitas nyeri. ${ }^{2}$

Regio periaquaduktal dan mesensefalon periventrikular berperan dalam sistem analgesia (sistem inhibisi nyeri). Signal dari regio ini ditransmisikan melalui nukleus di pons dan medula , ke kornu dorsalis dari medula spinalis, untuk memblok sensasi nyeri. Neurotransmiter yang berperan dalam supresi nyeri adalah opiat endogen seperti beta endorpin, begitu juga dengan serotonin dan GABA (gama amino butiryc acid) menurunkan sensasi nyeri. ${ }^{2}$

Persepsi nyeri pada neonatus berdasarkan sinyal nosiseptif, hal ini berarti adanya deteksi dan transmisi informasi tentang keberadaan dan kualitas stimulus nyeri (dari sistem syaraf perifer) ke otak. Jalur nosiseptif ini telah berkembang sepenuhnya sejak usia gestasi 2224 minggu. ${ }^{4}$ Sebaliknya sistem inhibisi nyeri pada neonatus belum berkembang sempurna, karena itu neonatus dapat merasakan nyeri yang lebih berat dibandingkan anak pada situasi yang sama. ${ }^{4,6}$

\section{The Gate Control Theory (teori Kontrol Pintu Gerbang)}

Teori ini menerangkan bahwa pada setiap kornu dorsalis medula spinalis terdapat mekanisme menyerupai pintu gerbang yang menginhibisi atau memfasilitasi aliran sinyal medula spinalis sebelum menimbulkan persepsi dan respon terhadap nyeri. Serabut syaraf yang berdiameter besar cenderung menutup pintu sehingga sinyal nyeri tidak dapat masuk melalui medula spinalis sedangkan serabut syaraf berdiameter kecil cenderung membuka pintu sehingga sinyal nyeri dapat masuk melalui medula spinalis ke otak. ${ }^{12}$ Teori ini menunjukkan bahwa sinyal nyeri dapat dipengaruhi dengan cara menstimulasi lokasi nyeri perifer misalnya dengan membawa signal raba (mekanoreseptor) dan dengan cara menstimulasi pengeluaran opioid endogen (opioid mediated) sehingga pintu akan tertutup dan akhirnya dapat mengurangi rasa nyeri. ${ }^{13}$

\section{Jenis Tindakan Invasif Minor dan Skala Nyeri untuk Neonatus}

Pada perawatan rutin, neonatus sering mengalami perasaan nyeri dalam hal beberapa tindakan invasif minor, seperti pengambilan sampel darah dengan menusuk tumit, pungsi vena dan arteri, pungsi lumbal, insersi kateter vena dan arteri, insersi nasogastrik, akses vena sentral, pemasangan kateter umbilikal, injeksi intramuskular atau subkutan, suction endotrakeal dan sirkumsisi. Tindakan-tindakan tersebut diatas sering dilakukan di neonatal intensive care unit. ${ }^{2,14}$

Nyeri merupakan fenomena subjektif bagi neonatus, sehingga diperlukan skala nyeri, yang umumnya merupakan kombinasi antara perubahan tingkah laku dan perubahan fisiologis. Beberapa skala nyeri untuk neonatus yang dapat digunakan adalah NIPS (neonatal infant pain scale), PIPP (premature infant pain profile), CRIES (crying, requires increased 
Sari Pediatri, Vol. 8, No. 2, Agustus 2006

oxygen administration, increased vital signs, expression; sleeplessness), N-PASS (neonatal pain, agitation and sedation scale). ${ }^{4}$

\section{Analgesia Nonfarmakologis}

Analgesia nonfarmakologis yang dapat digunakan saat tindakan invasif minor pada neonatus.

\section{Glukosa / sukrosa}

Beberapa penelitian telah memperlihatkan bahwa pemberian glukosa oral 2 menit sebelum tindakan invasif minor dapat mengurangi rasa nyeri pada neonatus. Jatana dkk (2003) telah meneliti efek analgesia dari glukosa oral pada neonatus aterm yang sehat . Mereka membandingkan berbagai konsentrasi glukosa $(10 \%, 25 \%$ dan $50 \%)$ dengan air steril dan ASI masing-masing sebanyak $1 \mathrm{ml}$, dalam hal efek analgesia pada neonatus saat pengambilan sampel darah dengan menusuk tumit. Pemberian ASI dan larutan glukosa $10 \%$ memiliki efek menurunkan respon fisiologis dan tingkah laku lebih rendah dibandingkan dengan konsentrasi glukosa 25\% dan 50\%. ${ }^{8}$ Sedangkan Gradin dkk (2002) membandingkan penggunaan $1 \mathrm{ml}$ glukosa oral $30 \%$ dibandingkan dengan krim EMLA (euthetic mixture local anasthethic) pada neonatus saat pengambilan sampel darah dengan pungsi vena. Hasilnya keduanya menurunkan skor nyeri dan lama menangis, hanya pada grup glukosa lebih bermakna dalam penurunan skor nyeri dan lama menangis dibandingkan dengan grup EMLA. ${ }^{9}$ Selain itu glukosa oral juga memiliki beberapa keuntungan yaitu hanya butuh waktu yang pendek sejak diberikan dan ditoleransi baik oleh neonatus cukup bulan, serta kemasannya telah tersedia di rumah sakit atau apotik. ${ }^{9,15}$ Selain glukosa, larutan sukrosa juga dapat digunakan untuk mengurangi rasa nyeri pada neonatus. Konsentrasi sukrosa yang dipakai juga bervariasi dari $24-70 \%$ dan semuanya secara signifikan menurunkan skor nyeri dan lama menangis pada neonatus saat tindakan invasif minor, bila dibandingkan dengan air steril. ${ }^{16}$

Efek analgesia glukosa atau sukrosa ini diduga akibat pelepasan beta endorpin (merupakan hormon opiat endogen yang diproduksi sendiri oleh tubuh dan mirip sifatnya dengan morfin) ${ }^{17,18}$ dan mekanisme preabsorpsi dari rasa manis., ${ }^{9,19}$ Beta endorpin dihasilkan oleh fetus pada saat lahir oleh glandula pituitari, hipotalamus dan melalui aliran darah bekerja seperti hormon dalam fetal dan neonatal distres oleh karena berikatan dengan reseptor di otak serta mengatur regulasi perasaan nyeri. ${ }^{17,18,20}$

\section{Pacifier}

Peran pacifier sebagai analgesia saat tindakan invasif minor pada neonatus telah dibuktikan oleh Carbajal dkk (1999). Penelitian ini membandingkan antara pemakaian glukosa atau sukrosa saja dengan glukosa / sukrosa ditambah pacifier. Hasilnya grup yang mendapatkan glukosa / sukrosa yang mendapat pacifier memiliki skor nyeri yang lebih rendah dibandingkan dengan tanpa pacifier. ${ }^{15}$

Pada suatu metaanalisis (2003) menunjukkan bahwa glukosa $12,5 \%$ dan 33\% ditambah pacifier dan sukrosa $12 \%$ - 24\% ditambah pacifier menurunkan secara bermakna lama menangis dan skor nyeri dibandingkan glukosa/sukrosa saja dan air steril. ${ }^{16}$ Analgesia yang terjadi setelah pemberian pacifier dan penambahan sukrosa ternyata menyebabkan terjadinya blokade afferen spinal pada daerah kornu dorsalis medula spinalis. ${ }^{21} \mathrm{Hal}$ ini telah dibuktikan terlebih dahulu oleh Ren dkk (1997) pada bayi tikus. ${ }^{22}$

Gunnar dkk (1984) telah meneliti efek pacifier terhadap tingkah laku dan respon adrenokortikal dari neonatus yang disirkumsisi. Pada neonatus yang memakai pacifier terjadi penurunan lama menangis lebih kurang 40\% dibandingkan dengan yang tidak memakai pacifier, namun perubahan adrenokortikal tidak nyata. ${ }^{23}$ Mekanisme yang jelas mengapa pacifier dapat menurunkan nyeri masih terus diteliti. Pengisapan menyebabkan neonatus dapat mengontrol suatu stimulus yang datang (stimulasi oral) melalui aktivitas yang dilakukan bayi. ${ }^{15}$ Blass EM dkk menunjukkan bahwa analgesia yang diinduksi dengan pengisapan tidak dipengaruhi oleh sistem opioid. ${ }^{24}$

\section{Menyusui}

Menyusui yang diberikan 2 menit sebelum dan selama tindakan invasif minor terbukti efektif menurunkan respon terhadap nyeri pada neonatus. ${ }^{25}$ Carbajal dkk (2003) telah meneliti efek menyusui pada neonatus sewaktu pengambilan sampel darah dibandingkan dengan air steril, glukosa $30 \%$ ditambah pacifier, atau 
hanya dipeluk oleh ibunya tanpa disusui. Penelitian ini membuktikan bahwa menyusui dan pemberian glukosa dengan pacifier menurunkan skor nyeri secara bermakna dibanding kedua grup yang lain. ${ }^{10}$ Gray $\mathrm{dkk}$ (2002) menemukan bahwa menyusui merupakan analgesia yang poten untuk neonatus saat pengambilan sampel darah dengan menusuk tumit. Lama menangis dan perubahan mimik wajah, lebih rendah pada grup menyusui dibandingkan dengan grup kontrol. Mekanisme menyusui dapat berfungsi sebagai analgesia masih belum jelas, namun diduga dipengaruhi juga oleh sistem opioid. ${ }^{21}$

\section{Skin to skin contact}

Skin to skin contact dengan ibu bayi merupakan salah satu cara untuk mengurangi rasa nyeri saat tindakan invasif minor pada neonatus. ${ }^{26}$ Cara skin to skin contact sama dengan kangaroo mother care untuk bayi prematur. ${ }^{27}$ Keefektifan skin to skin contact bergantung kepada 3 faktor yaitu ibu dan bayi harus dalam posisi yang menyenangkan dan santai, membutuhkan waktu 10-15 menit serta ibunya mesti ada pada saat tindakan invasif minor tersebut. ${ }^{28}$ Penelitian yang dilakukan oleh Gray (2000) dkk membagi secara acak neonatus dalam 2 kelompok, yaitu kelompok yang mendapatkan skin to skin contact selama $10-15$ menit dan kontrol yang tidak ada kontak pada saat menusuk tumit. Hasilnya didapati bahwa skin to skin contact mengurangi menangis dan perubahan mimik masingmasing sebesar $82 \%$ dan $65 \%$. Skin to skin contact juga mencegah peningkatan frekuensi jantung. ${ }^{26}$

\section{Stimulasi Multisensori}

Stimulasi multisensori merupakan gabungan dari beberapa stimulasi sensori, yang terdiri dari stimulus taktil, vestibular, olfaktori, gustatori, auditori dan visual. ${ }^{29}$ Stimulasi multisensori ini telah diteliti dapat menurunkan skor nyeri pada neonatus. Penelitian oleh Bellieni dkk (2002) menunjukkan bahwa stimulasi sensori dengan gabungan glukosa oral dapat menurunkan skor nyeri, yaitu dengan cara: membaringkan neonatus pada tempatnya dengan fleksi lengan dan kaki tetapi bebas bergerak, melihat wajah neonatus secara dekat dan simultan, mengurut wajah dan punggung neonatus, berbicara kepada neonatus secara lembut, memakai bau-bauan (parfum bayi) pada tangan ibu agar tercium oleh neonatus, meneteskan glukosa ke lidah neonatus. ${ }^{30}$ Mekanisme stimulasi multisensori sebagai analgesia adalah adanya stimulasi sensori mencegah sinyal syaraf nosiseptif untuk masuk otak sehingga dapat mengurangi rasa nyeri ( the gate control theory). ${ }^{29,30}$

\section{Kesimpulan}

Nyeri pada neonatus sering menjadi masalah oleh karena neonatus tidak dapat memberi tahu rasa nyeri dan adanya kesulitan kapan sebaiknya memberi analgesia pada neonatus. Tindakan invasif minor pada neonatus juga menimbulkan rasa nyeri dan perlu diberikan analgesia. Analgesia nonfarmakologis seperti glukosa/sukrosa, pacifier, menyusui, skin to skin contact dan stimulasi multisensori dapat dipakai untuk tindakan invasif minor pada neonatus sehingga dapat dihindarkan pemakaian analgesia farmakologis.

\section{Daftar Pustaka}

1. Selbst SM. Sedation and analgesia. Dalam: Fleisher GR, Ludwig S, Henretig FM, Ruddy RM, Silverman BK, penyunting. Texbook of Pediatric Emergency Medicine. Edisi ke-4. Philadelphia: Lippincott William \& Wilkins,2000. h. 59-69.

2. Mathew PJ, Mathew JL. Assessment and management of pain in infants. PostgradMed J 2003;79:438-48.

3. Bar RG. Reflection on measuring pain in infants: dissociation in responsive systems and "honest signaling". Arch Dis Child Fetal Neonatal 1998:79:152-6.

4. Infant pain. Pediatric Nursing, April 2003. Didapat dari: http://www.nursingcenter.com/prodev/ce.

5. Djik MV, Simons S, Tibboel D. Pain assesment in neonates. Paed Perinatal Drug Ther 2004;6:97-103.

6. Pain management and sedation. Intensive care nursery house staff manual. Didapat dari: http://www. ucsfhealth. org/childrens/health_professionals/manuals/50_Pain.pdf

7. Porter FL, Wolf CM, Miller JP. Prosedural pain in newborn infants: The influence of intensity and development. Pediatrics 1999;104:1-10.

8. Jatana LCS, Dalal SLS, Wilson CCG. Analgesic effect of oral glucose in neonates. MJAFI 2003;59:100-4.

9. Gradin M, Eriksson M, Holmqvist G, Holstein A, Schollin J. Pain reduction at venipuncture in newborns: oral glucose compared with local anesthetic cream. Pediatrics 2002;110:1053-7. 
Sari Pediatri, Vol. 8, No. 2, Agustus 2006

10. Carbajal R, Veerapen S, Couderc S, Jugie M, Ville Y. Analgesic effect of breast feeding in term neonates: randomized controlled trial.BMJ 2003;326:1-5

11. Anand KJS, Phil D, Hickey PR. Pain and its effects in the human neonate and fetus. The $\mathrm{N}$ Engl J Med 1987;19:1321-9.

12. Gate control theory of pain. Didapat dari: http:// www.en.wikipedia.org/wiki/Gate_control_theory_of_pain

13. Jobonga. Gate control theory. Massage \& natural therapies clinic. Didapat dari http://www.usenature.com/painarticle.htm

14. Anand KJS, Phil D and the International evidence based group for neonatal pain. Consensus statement for the prevention and management of pain in the newborn. Arch Pediatr Adolesc Med 2001;155:173-80 .

15. Carbajal R, Chauvet X, Couder S, Martin Mo. Randomized trial of analgesic effects of sucrose, glucose, and pacifiers in term neonates.BMJ 1999;319:1393-7.

16. Pitchard D. Reducing pain during blood sampling in infants. April 2003. Didapat dari: http://www. clinicalevidence.org/ceweb/conditions/chd/0313/0313_ background.

17. Endorphin. Didapat dari: http://en.wikipedia.org/wiki/ Endorphin

18. Todd T. Endorphins and Analgesia. Didapat dari: http:/ lwww.members.aol.com/endorphins

19. Johnston CC, Fillion F, Snider L. Routine sucrose analgesia during the first week of life in neonates younger than 31 weeks postconcepional age. Pediatrics 2002; 110: 523-8.

20. Schul. Z. Endogenous analgesics ?. Dalam: Forth W, Martin E, Peter K, penyunting. The Relief of pain. Munich: Hoechst Aktiengesellschaft, 1986. h.16-7.
21. Gray L, Miller LW, Philipp BL, Blass EM. Breastfeeding is analgesic in healthy newborns. Pediatrics 2002; 109:590-3.

22. Ren K, Blass EM, Zhou Q, Dubner R. Suckling and sucrose ingestion suppress persistent hyperalgesia and spinal Fos expression forepaw inflammation in infant rats. Proc Natl Acad Sci 1997;94:1471-5.

23. Gunnars MR, Fisch RO, Malone S. The effect of a pacifying stimulus on behavioral and adrenocortical responses to circumsision in the newborn. J Am Acad Child Psych 1984:23;34-8.

24. Blass EM, Shide DJ, Zaw-Mon C, Sorrentino J. Mother as shield: differential effects of contact and nursing on pain responsiry in infant rats-evidence for nonopioid mediation. Behav Neurosci.1995;109:342-3.

25. Potter B, Rindfleisch K. Breastfeeding reduces pain in neonates. J. Fam. Prac. May 2003; 52:13-4.

26. Gray L, Watt L, Blass E. Skin to skin contact is analgesic in healthy newborns. Pediatrics 2000;105:1-6.

27. Ruiz Pelaez JG, Charpak N, Cuervo LG. Kangaroo mother care, an example to follow from developing countries. BMJ 2000; 329:1179-81.

28. Gibbin S. Skin to skin contact with their mothers reduced pain reactions in healthy newborn infants during a heel lance. Commentary, Evid Based Nurs 2000; 105:73.

29. Bellieni CV, Buonocore G, Nenci A, Franci N, Cordelli DM, Bagnoli F. Sensorial saturation: An effective analgesic tool for heel prick in preterm infants. Biol Neonate 2001;80:15-8.

30. Bellieni CV, Bagnoli F, Pettone S dkk. Effect of multisensory stimulation on analgesia in term neonates: A randomized controlled trial. Pediatr Res 2002;51:460-3. 